\title{
Avaliação ambiental de Sistemas de aproveitamento de água pluvial - um mapeamento da literatura
}

\author{
BRANDÃO, Verônica Ribeiro ${ }^{1}$ \\ CAMPOS, Marcus André Siqueira Campos ${ }^{2}$ \\ 1UFG, Goiânia Brasil, vrb.eng@gmail.com \\ 2UFG , Goiânia, Brasil marcussiqueira@yahoo.com.br
}

\begin{abstract}
Resumo
O aproveitamento de água pluvial surge como uma forma de promover a conservação de água em edificações e vem se destacando como medida mitigadora de impactos ambientais. Este trabalho traz a metodologia utilizada na realização de um mapeamento sistemático de literatura (MSL) para análise de ciclo de vida de sistemas prediais de aproveitamento de água pluvial em habitações de interesse social. Partindo das análises realizadas por meio do MSL, foi possível verificar as lacunas do conhecimento que existem na área abordada, assim como os aspectos que podem ser aderidos à pesquisa em questão. Observou-se que o tema é ainda relativamente recente, uma vez que os artigos encontrados datam dos últimos 7 anos. Além disso, verificou-se que os Estados Unidos é o país que mais tem abordado o tema, apontando ainda que no Brasil, há apenas uma pesquisa sobre o assunto. Além disso, as pesquisas apresentadas embasaram seus métodos com abordagens de ACV diferentes. A metodologia utilizada para o mapeamento sistemático de literatura se apresentou satisfatória para atender os objetivos deste trabalho.
\end{abstract}

Palavras-Chave: Mapeamento Sistemático de Literatura. Aproveitamento de Água Pluvial. Análise de Ciclo de Vida. Habitações de Interesse Social.

\begin{abstract}
The use of rainwater appears as a way to promote water conservation in buildings and it has been highlighted as a mitigating action of environmental impacts. This work brings the methodology used to perform a systematic literature mapping (SLM) for the life cycle analysis of rainwater harvesting systems in social housing. Based on the analyzes performed through the SLM, it was possible to verify the knowledge gaps that exist in the area addressed, as well as the aspects that can be adhered to the research in question. It was observed that the theme is still relatively recent, since the articles found date back to the last 7 years. In addition, it was found that the United States is the country that has most addressed the issue, pointing out that in Brazil, there is only one research on the subject. In addition, the research presented supported their methods with different approaches to stroke. The methodology used for the systematic mapping of the literature was satisfactory to meet the objectives of this work.

Key-Words: Systematic literature mapping, rainwater harvesting systems, Life cycle Analysis, low income housings
\end{abstract}




\section{Introdução}

De acordo com a Declaração Universal de Direitos Humanos, todo ser humano tem direito à um padrão de vida que the assegure habitação e não pode arbitrariamente ser privado de sua propriedade (ONU, 1948, p 10 e 13). No entanto, no Brasil é possível identificar diversas conjunturas em que um padrão mínimo de qualidade não se faz cumprir. Conforme os dados da Fundação João Pinheiro (2012), no ano de 2009 observou-se um déficit habitacional estimado em 5,998 milhões de domicílios, dos quais $84,8 \%$, localizavam-se em áreas urbanas. Isto representou um acréscimo de 459 mil unidades habitacionais no déficit habitacional brasileiro, se comparado ao ano anterior.

Dessa forma destaca-se a importância em se promover programas que apoiam a diminuição do déficit habitacional no Brasil. Diante da problemática desses quase 6 milhões de famílias e com o objetivo de saná-la pelo menos parcialmente, naquele mesmo ano o Governo Federal criou o "Programa Minha, Casa Minha Vida", que ainda hoje, oferece condições atrativas para o financiamento de residências em áreas rurais e urbanas, para famílias de baixa renda. Com o apoio dos governos estaduais, empresas e entidades sem fins lucrativos, o programa já conseguiu entregar mais de um milhão de moradias e até 2014 estavam previstas a entrega de mais 2 milhões de casas e apartamentos (CEF, 2015).

Porém, a implantação desses conjuntos cria naquela determinada localidade uma demanda antes não existente. Fazendo-se necessário a implantação de infraestruturas, que geram impactos ambientais e sociais relevantes para o ecossistema urbano e que devem portanto, ser considerados.

Para mitigar tais impactos, estão disponíveis no mercado uma série de ferramentas e tecnologias aplicáveis como por exemplo o uso de materiais sustentáveis, dispositivos redutores de consumo de água, utilização de energia solar, certificações de sustentabilidade, dentre outros. Porém, tais alternativas não são ainda amplamente empregadas nesses programas de habitação social no Brasil.

Neste contexto, o aproveitamento de água pluvial vem se destacando como medida mitigadora de impactos ambientais, como estresse hídrico, contribuindo com a retenção e detenção de água de chuva e diminuindo a demanda de água potável (YRUSKA, 2008). Autores como Marinoski (2011) e Nazer et.al. (2010) começaram a fazer suas tomadas de decisão baseando-se não apenas em aspectos econômico, como também ambientais (MANO, 2004).

Seguindo essa linha, a análise de ciclo de vida, uma ferramenta ainda brevemente abordada, avalia os impactos ambientais gerados em cada etapa da produção, uso e descarte de qualquer produto analisado, possibilitando identificar as fases mais ou menos impactantes ao longo da vida útil do objeto de estudo. Isso confere ao avaliador a oportunidade de identificar os potenciais pontos de redução dos impactos ambientais ou ainda comparar dentre as possíveis estratégias de interesse, qual a mais viável para determinada situação (MARINOSKI, 2010).

A partir dessas premissas surge a proposta do trabalho no interesse em reduzir tais impactos. Este trabalho traz a metodologia utilizada na realização de um mapeamento sistemático de literatura para análise de ciclo de vida de sistemas prediais de aproveitamento de água pluvial em habitações de interesse social.

O Mapeamento Sistemático de Literatura - MSL consiste em uma metodologia que padroniza a busca por literatura, independentemente da área. Ela permite dessa forma, realizar uma pesquisa de bibliografia que proporciona uma visão global do tema abordado. Isto permite aperfeiçoar qualitativamente a revisão bibliográfica, já que aprimora o processo de busca por literatura. Ela permite identificar os temas já abordados em uma determinada área de interesse, assim como as lacunas de pesquisa no contexto internacional, proporcionando situar o trabalho nesta conjuntura. Isto pode contribuir consideravelmente para comunidade científica (BAILEY et al., 2007; ENGSTRÖM; RUNESON, 2011) já que a partir dessa metodologia, pesquisas podem ser continuadas ou soluções 
inéditas podem ser propostas (RUIZ; GRANJA, 2013).

A partir desse mapeamento, resultados como a quantidade de artigos encontrados, os países em que as pesquisas se desenvolveram e as metodologias utilizadas em cada uma destas, podem ser obtidos.

Este artigo tem como objetivo geral identificar o estado da arte de análises de ciclo de vida realizadas em Sistemas de Aproveitamento de Água Pluvial em periódicos internacionais.

\section{Metodologia}

Neste trabalho a metodologia de Mapeamento Sistemático de Literatura utilizada, segue o padrão aplicado por Ruiz e Granja (2013) e Costa, Staut e Ilha (2014), conforme o método empregado por Kitckenham et al. (2010), que pode ser visualizado na Figura 1.

Figura 1 - Delineamento do Mapeamento Sistemático de Literatura

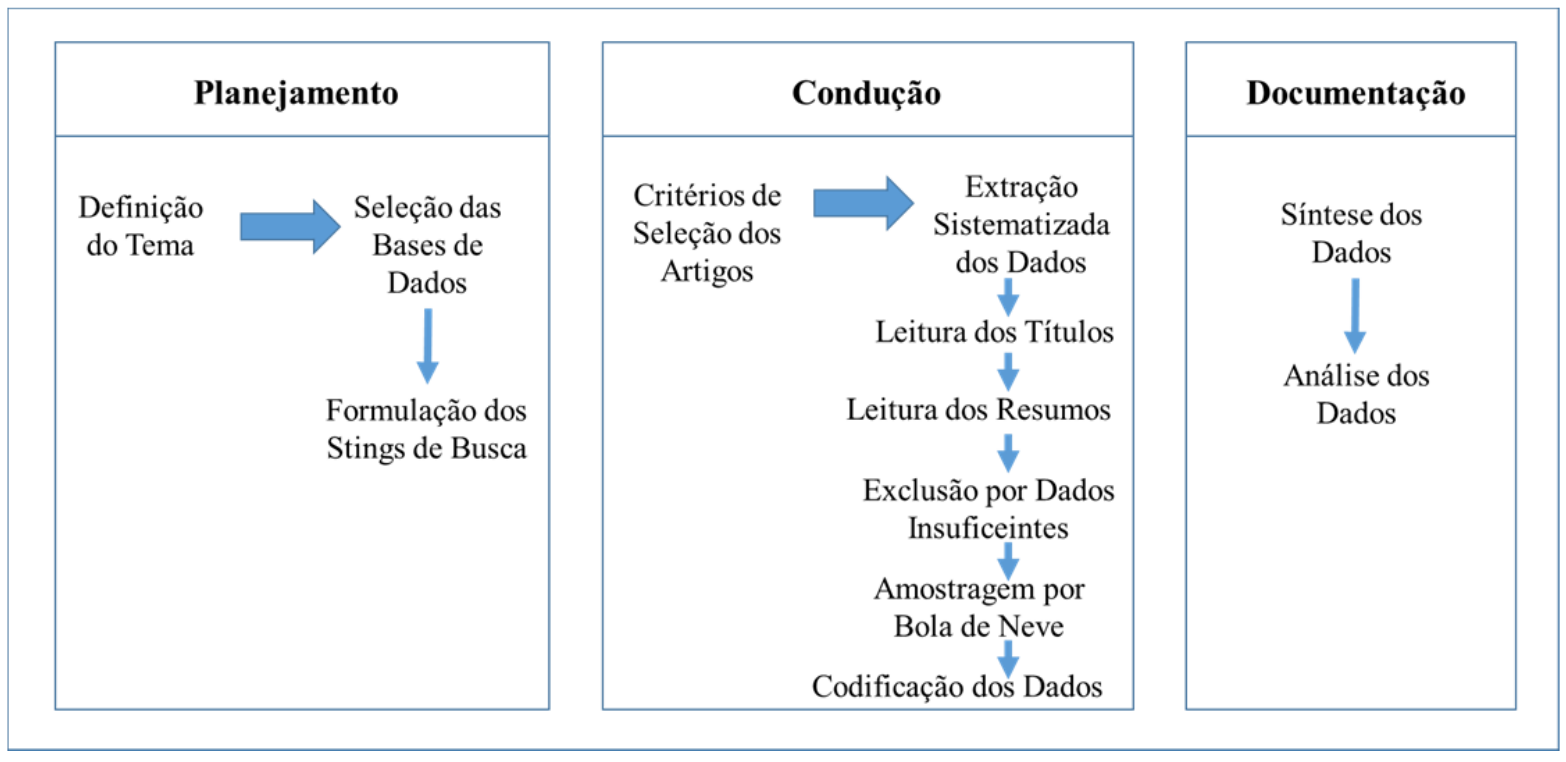

Fonte: Adaptado de Costa, Staut e Ilha (2014).

\subsection{Definição das Bases de Dados}

As bases de dados são, para o pesquisador, uma das fontes de dados bibliográficos de considerável relevância, pois disponibilizam um grande volume de conteúdo científico em um único local. Portanto, deve-se levar em consideração a confiabilidade das bases adotadas, de forma a priorizar a pré-seleção qualitativa dos artigos buscados. A escolha das bases de dados aqui utilizadas, acordou-se com a área em que a pesquisa se contextualiza: Engenharias, bem como com a disponibilidade de acesso às mesmas. Para este trabalho utilizou-se o Scopus, o Science Direct, o Web of Science e o Engineering Village como plataformas para a obtenção de literatura científica.

\subsection{Definição das Palavras-Chave}

A definição das palavras-chave é prévia à formulação dos strings de busca e sugere porém, um patamar mais amplo do que será abordado na pesquisa. Neste trabalho, este parâmetro foi realizado a partir da escolha do tema, resultando-se no seguinte conjunto: Rainwater, RWH - Rainwater Harvesting, Life Cycle e LCA - Life Cycle Assessment. Estas seriam as palavras mais importantes de serem identificadas, pois os artigos selecionados devem abordar a ACV em SPAAPs.

\subsection{Elaboração dos Strings}


A definição dos strings é uma das etapas mais minuciosas do processo de mapeamento sistemático de literatura, pois é ela que determina o escopo de obtenção dos artigos, estabelecendo-se portanto a amplitude da bibliografia a ser obtida, assim como a correspondência com os interesses do pesquisador. Para esta pesquisa foram realizadas algumas tentativas de strings antes de se encontrar um satisfatório para esta revisão:

- rainwater AND life cycle

- rainwater harvesting AND social houses

- rainwater harvesting AND life cycle assessment

- $\quad$ rwh AND Ica

- rainwater harvest ${ }^{*}$ AND life cycle

- rainwater harvest* $A N D$ Ica

Ao final das tentativas, o string estabelecido foi: (rainwater OR rwh) AND (life cycle OR Ica), o qual foi utilizado na mesma configuração para todas as bases de dados acessadas.

\subsection{Extração Sistematizada dos Dados}

A extração sistematizada é feita para que sejam comparados entre si todos os dados dos artigos obtidos através das buscas nas bases de dados. Para cada base de dados há uma especificidade na forma de extração dessas informações. Nesta etapa, visou-se obter esses documentos nos formatos mais simplificados possível, de maneira a facilitar a etapa de codificação dos dados extraídos. Neste trabalho, os dados obtidos foram em formato de .txt (bloco de notas), ris ou .csv.

\subsection{Codificação dos Dados}

Para que se possa realizar a seleção e posterior análise dos artigos identificados, de modo mais eficiente, é importante que os dados dos artigos obtidos sistematicamente sejam padronizados em um único formato e forma. Este processo é feito através de programas computacionais que permitem a organização dos dados adquiridos nas diferentes bases de dados. Neste trabalho foram utilizados para padronização dos elementos analisados (título, autor, ano, resumo...) dos artigos, o Excel $₫$ como ferramenta de organização dos dados, o Sublime ${ }^{\circledR}$ e um link de envio e padronização dos dados.

\subsection{Processamento e Contabilização dos Dados Obtidos}

Após a extração e padronização de todos os dados, realizou-se a contagem de todos artigos obtidos, bem como foram selecionadas as publicações de interesse tanto para a pesquisa em geral, quanto para o mapeamento realizado: análise de ciclo de vida de sistemas prediais de aproveitamento de água pluvial.

Inicialmente ocorreu a exclusão de artigos baseados em critérios pré-estabelecidos, são estes:

- Artigos de 1997 e anteriores;

- Artigos com duplicidade;

- Incoerência com o tema abordado em função da leitura dos títulos e resumos.

Logo após esta etapa iniciou-se a leitura completa dos artigos, o que permitiu entre outras coisas excluir artigos que não possuíam dados suficientes ou que não se enquadravam no objetivo da pesquisa. Além disto, permitiu-se acrescentar artigos encontrados na amostragem por bola de neve (Snowball sampling). 
Para finalizar o mapeamento sistemático de literatura, realizou-se uma síntese e uma análise dos dados. Essa etapa permitiu identificar dentre os artigos selecionados, informações como por exemplo: principais temas abordados, anos com maior quantidade de publicações, tipos de publicação (congressos, periódicos, capítulos de livros...), números de publicações por ano, principais autores, dentre outros. Além disso, verificou-se também as lacunas de conhecimentos existentes, servindo assim para norte em futuras pesquisas.

\section{Resultados}

A primeira etapa consistiu no levantamento dos artigos aderentes. Conforme os critérios de inclusão e exclusão citados no item de metodologia, obteve-se 25 artigos, conforme descritos na Tabela 1.

Tabela 1 - Quantitativo de artigos nas Etapas do Mapeamento Sistemático de Literatura

\begin{tabular}{|l|c|}
\hline \multicolumn{1}{|c|}{ Etapa } & No de Artigos \\
\hline Artigos previamente selecionados & 6607 \\
\hline Artigos de 1997 e anos anteriores & -1605 \\
\hline Artigos com duplicidade & -238 \\
\hline Leitura de títulos & -4124 \\
\hline Leitura de resumos & -584 \\
\hline Artigos sem dados suficientes & -9 \\
\hline Leitura dos artigos completos & -23 \\
\hline Amostragem por bola de neve & 1 \\
\hline TOTAL & 25 \\
\hline
\end{tabular}

Partindo da obtenção dessas informações dos artigos aderentes, foram realizadas análises quantitativas e qualitativas. A primeira análise feita se refere ao número de publicações por autor, que á apresentada na Figura 2.

Figura 2 - Distribuição do número de publicações dos autores que mais produziram sobre o assunto abordado

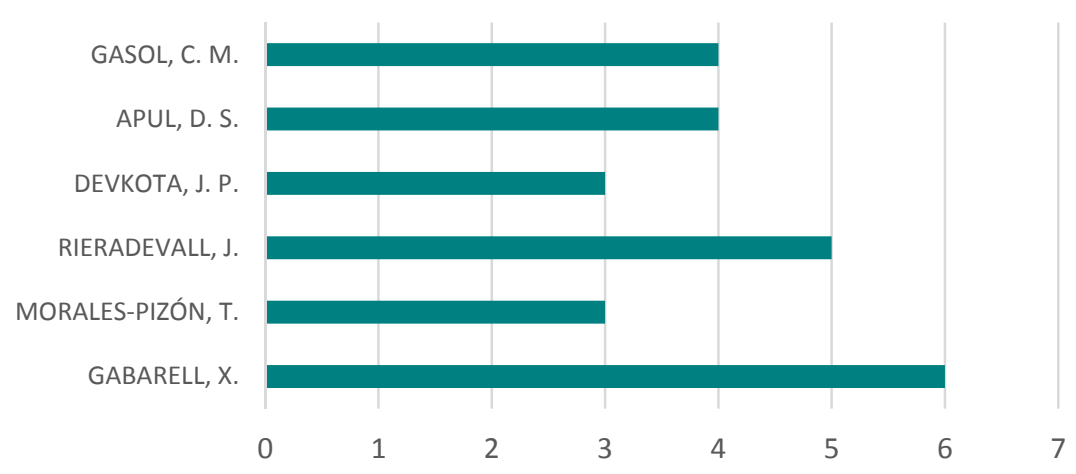

Observa-se que, do total de 78 autores, apenas 6 apresentaram 3 ou mais publicações relacionadas com o tema pesquisado. Identificou-se que destes autores apresentados, existem dois maiores grupos de pesquisa que realizam suas publicações em conjunto. $O$ autor com mais publicações Gabarrell, realizou todos os seus trabalhos com o perfil residencial, em estudos de caso na Espanha (VARGASPARRA; VILLALBA; GABARREL, 2013; ANGRILL et. al, 2012; 2017; MORALES-PINZÓN et. al, 2012, 2014, 2015). 
Seguido do levantamento dos autores, foram verificados os anos de publicação dos artigos aderentes e identificou-se que são pesquisas recentes, datando a partir do ano de 2010. Como os dados do mapeamento foram obtidos no início do ano de 2017 , poucas publicações haviam sido realizadas neste ano em questão, portanto, este é um dos fatores que contribui para que o número de artigos publicado neste ano seja ainda pequeno. No entanto, observa-se o desenvolvimento crescente do tema ao longo dos anos analisados, com 32\% dessas publicações ocorrendo nos anos de 2015 e 2016 e $12 \%$ das publicações ocorrem até fevereiro de 2017, conforme apresentado pela Figura 3. É possível observar uma tendência deste aumento, nos últimos anos.

Figura 3 - Distribuição das publicações ao longo dos anos

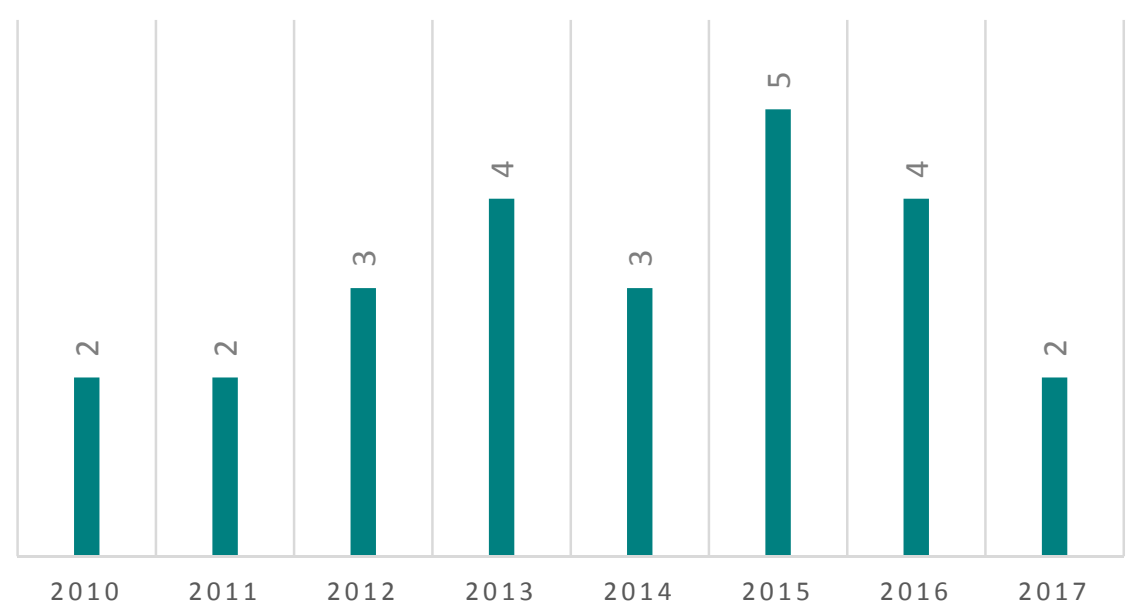

Dos 25 artigos selecionados pelo mapeamento sistemático de literatura, foi possível identificar quarenta instituições de autores que participaram das pesquisas consideradas. Para realizar esta análise, contabilizou-se individualmente cada autor de cada publicação. Este dado nos permite visualizar as Instituições com os maiores grupos de pesquisas e publicação, bem como demonstra ainda, os principais países que investiram em pesquisa na área considerada. A Figura 4 apresenta as 6 principais Instituições dos autores participantes da produção dos artigos selecionados.

Para obter o valor de produção de cada instituição, atribuiu-se 1 ponto para cada autor de artigo publicado e aderido ao mapeamento. Dentre os grupos de pesquisas das universidades que se destacaram, pode-se citar a University of Toledo e a Universitat Autònoma de Barcelona. Os autores provenientes da University of Toledo foram participantes em 4 dos 25 artigos produzidos, enquanto que os autores da Universitat Autònoma de Barcelona participaram de produção de 6 , dos artigos aderentes. 
Figura 4- Instituições dos Autores

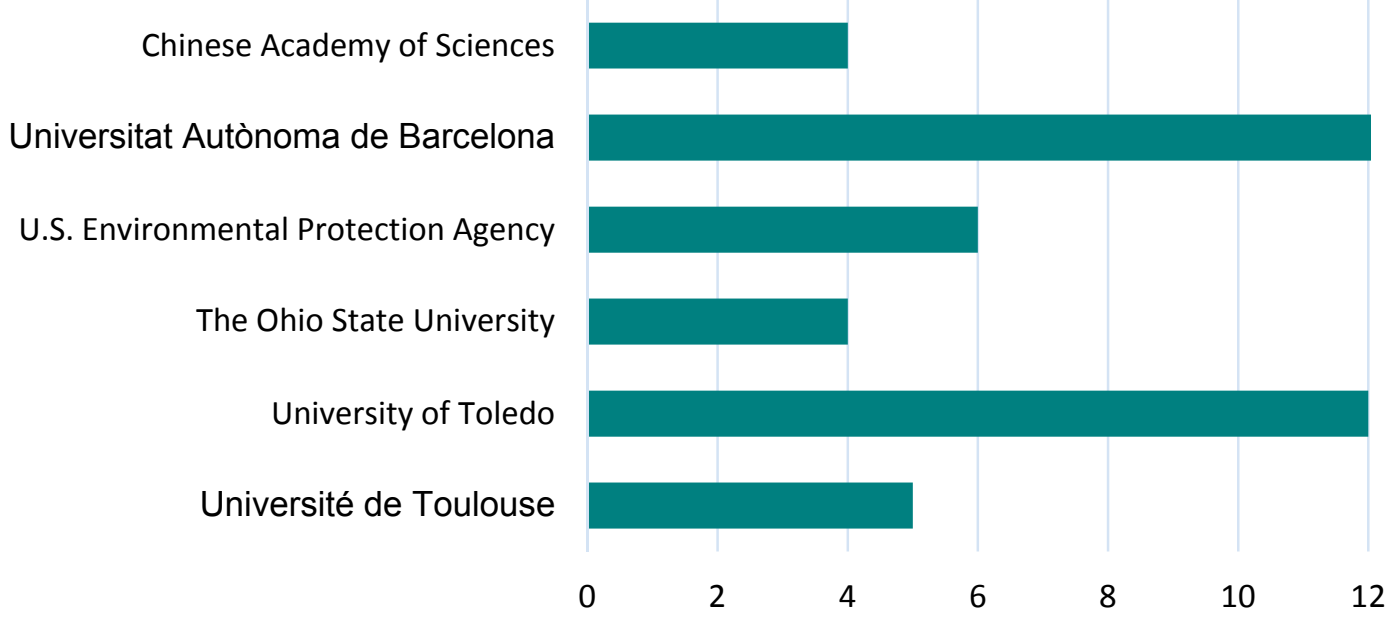

Para avaliar as instituições quanto aos países em que se localizam, foi atribuído novamente, um ponto para cada autor de cada artigo. Isso permitiu identificar que os Estados Unidos é o país que mesmo com um menor número de artigos publicados no tema, apresentou um maior número de autores pesquisando sobre o assunto, seguido da Espanha, conforme apresentado pela Figura 5.

Figura 5 Nacionalidade das Instituições

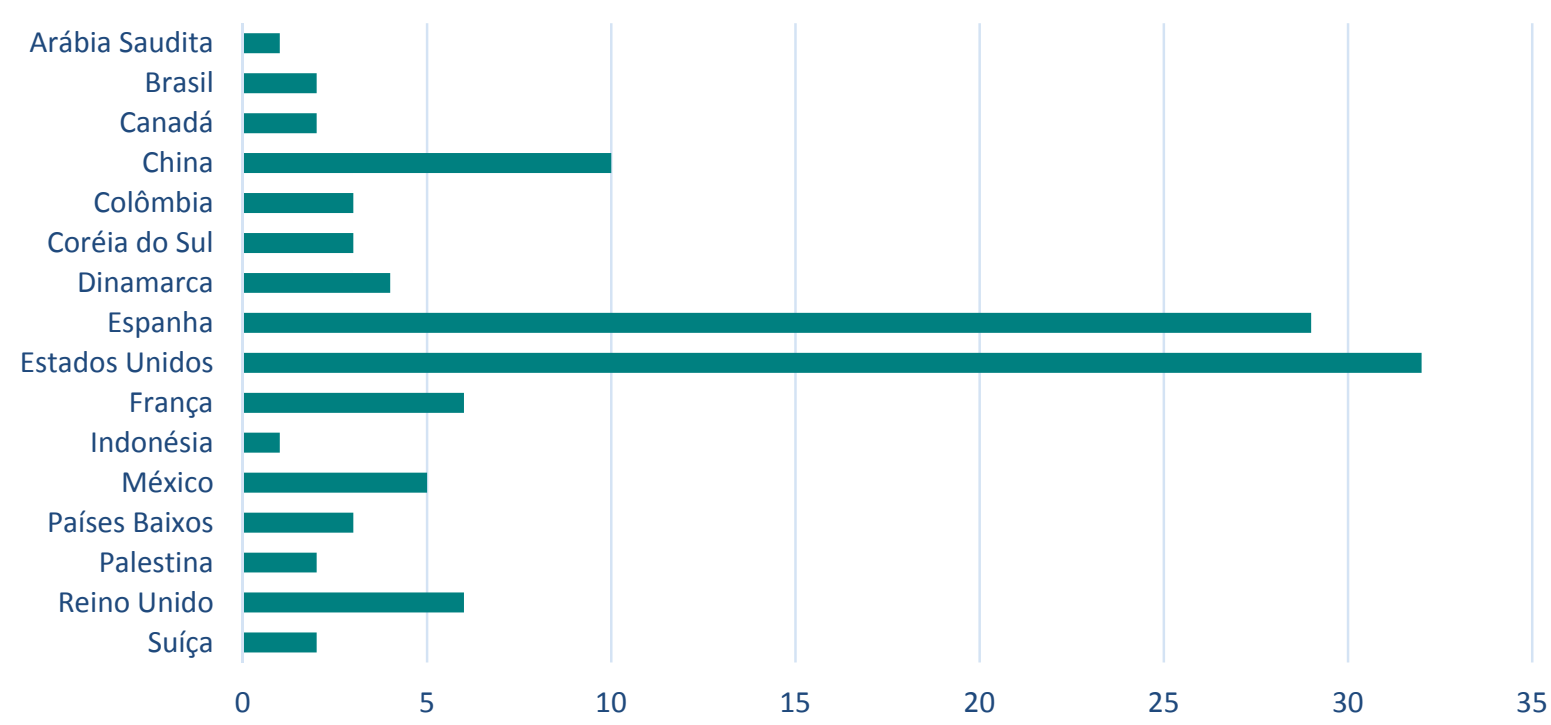

Para verificar as palavras-chave utilizadas nos artigos, foram contabilizados os números de aparições destas em todo o conjunto de artigos analisados. A palavra-chave com o maior número de aparições foi Rainwater harvesting, aparecendo em $72 \%$ dos artigos selecionados. As palavras-chave que seguem no ranking são Life cycle assessment e LCA, que apareceram em $40 \%$ e $24 \%$ dos artigos respectivamente. Apesar destes dois strings possuírem um mesmo significado literal, eles oferecem resultados distintos nas buscas nas bases de dados, dessa forma, considerou-os separadamente. No entanto, em relação ao contexto, ambos strings, juntamente com Life Cycle Assessment, apareceram também em $72 \%$ dos artigos adotados. A Figura 6 aponta as palavras-chave para o tema abordado no mapeamento que apareceram em pelo menos 2 artigos. 
Figura 6 - Palavras-Chave mais utilizadas

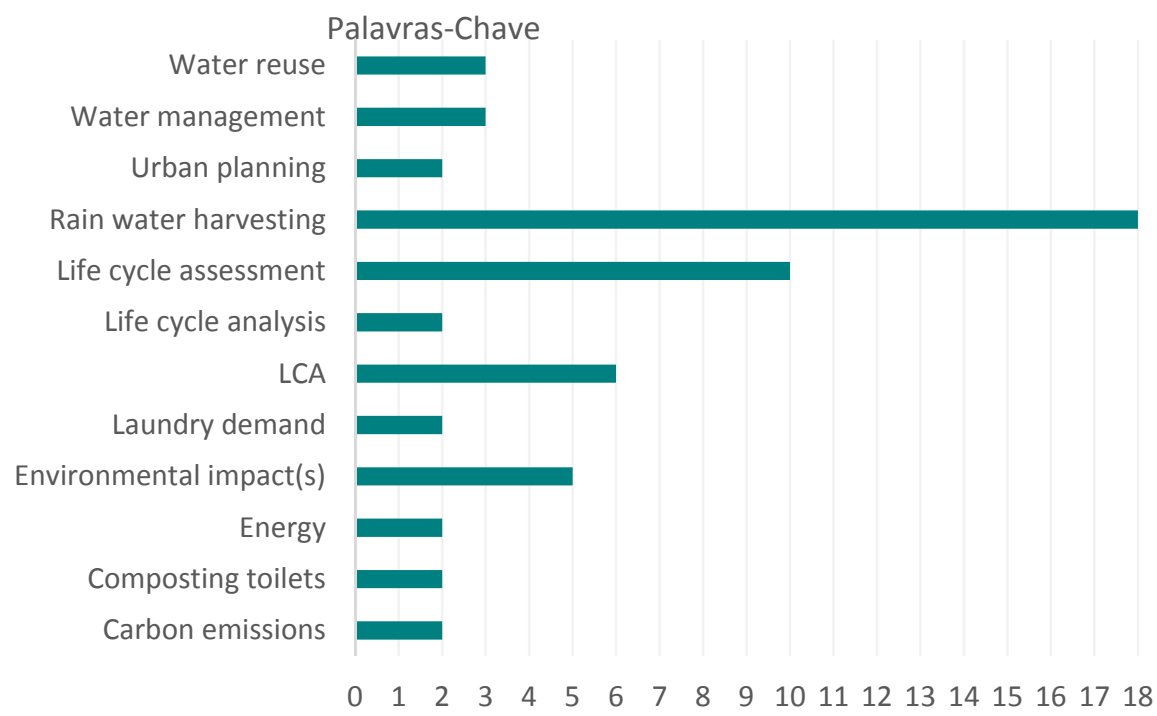

Verificou-se a aparição de 79 palavras chaves diferentes. que apenas os termos Rainwater Harvesting, Life Cycle Assessment, LCA, Environmental Impact e Composting Toilets apareceram em mais de um artigo. As outras palavras são pontuais, referentes a cada análise apresentada nos artigos.

Em relação aos meios de publicação desses artigos, verificou-se que apenas 1 deles foi publicado em congresso (SHAH et al., 2013), sendo o restante em periódicos. No entanto, mais relevante que identificar os locais de publicação, é apresentar seus índices de Journal Citation Reports (JCR), uma vez que por atribuição de notas para cada periódico, ele permite avaliar qualitativamente o local de publicação desses artigos. No total, 13 periódicos foram identificados e seus respectivos fatores de impacto JCR são apresentados na Figura 7.

Figura 7 - Origem dos artigos selecionados pelo MSL

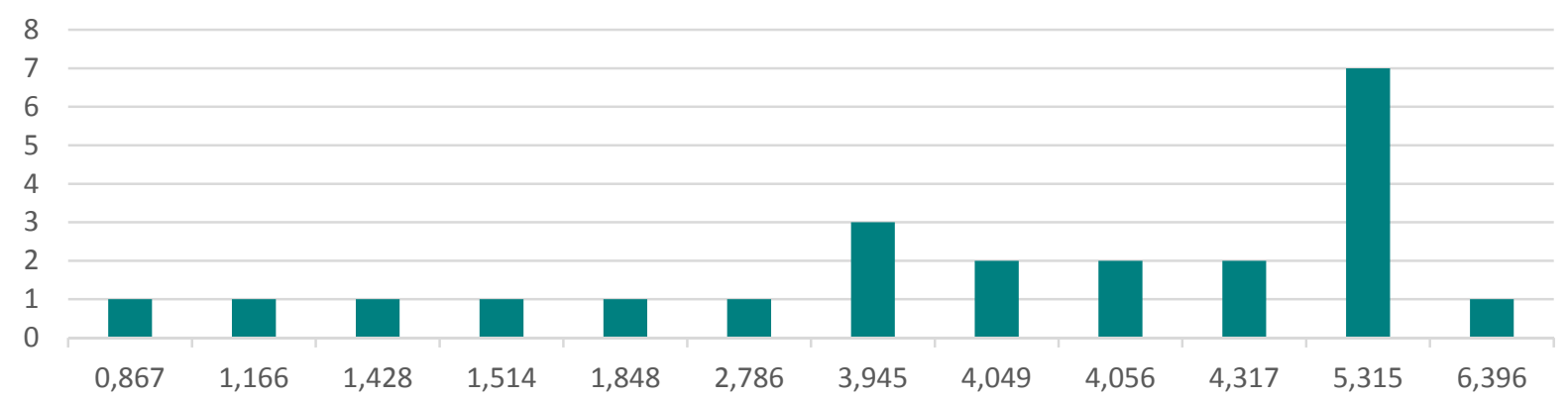

Dos artigos aderentes, dois não possuíam nota de JCR e foram indicados no gráfico com a sigla s.n., de sem nota (SHAH et al., 2013; MARINOSKI; GHISI, 2011). A média dos índices de cada artigo aderente corresponde ao valor de 3,908 e menos de um quarto destes artigos ficaram abaixo deste valor. Além disso, neste caso a maioria dos trabalhos foram publicados conforme a segunda melhor nota dos índices observados. Verificou-se que o Journal of Cleaner Production foi o que veiculou o maior número de artigos, totalizando 7 publicações (DEVKOTA; SCHLACHTER; APUL, 2015; DEVKOTA et al., 2015; MORALES-PINZÓN et al., 2015; GAO et al., 2016; GARCÍA-MONTOYA et al., 2016; GHIMIRE et al., 2017; CHANG; LEE; YOON, 2017) e possui um JCR de 5,315.

Os artigos foram analisados ainda em relação à sua estratégia de pesquisa quanto ao procedimento, 
conforme proposto por Gerhardt e Silveira (2009). Identificou-se que todos os artigos avaliados tratamse de estudo de caso.

Em seguida, foi verificado ainda os países em que os estudos de caso foram realizados. Das 25 pesquisas abordadas, 8 foram estabelecidas nos Estados Unidos (ANAND; APUL, 2011; DEVKOTA et al., 2013; SHAH et al., 2013; GHIMIRE et al., 2014; DEVKOTA; SCHLACHTER; APUL, 2015; DEVKOTA et al., 2015; JEONG et al., 2016; GHIMIRE et al., 2017), seguidas da Espanha com 6 trabalhos (ANGRILL et al., 2012; MORALES-PINZÓN et al., 2012; VARGAS-PARRA; VILLALBA; GABARRELL, 2013; MORALES-PINZÓN et al., 2014; MORALES-PINZÓN et al., 2015; ANGRILL et al., 2017). A Figura 8 apresenta os 9 países restantes que foram verificados.

Figura 8 - Países em que as pesquisas foram realizadas

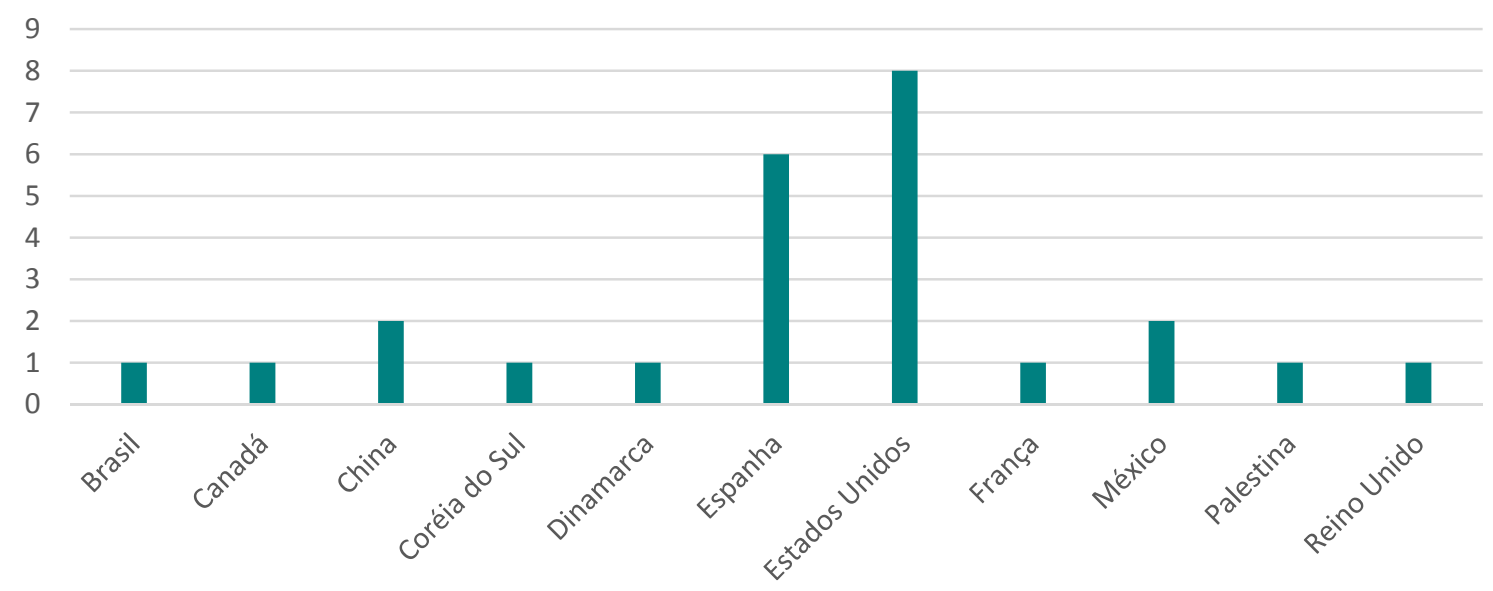

É importante ressaltar que metade dos artigos publicados nos Estados Unidos tem seus autores vinculados principalmente à University of Toledo (ANAND; APUL, 2011; DEVKOTA et al., 2013; DEVKOTA; SCHLACHTER; APUL, 2015; DEVKOTA et al., 2015).

Outro fator de relevante para esta análise é a tipologia das edificações que foram utilizadas como modelo para os estudos de casos das pesquisas apresentadas. Entre os artigos selecionados, diversas tipologias foram abordadas: escritórios (WARD; BUTLER; MEMON, 2011; DEVKOTA et al., 2013; DEVKOTA et al., 2015), edifícios escolares, universidades (ANAND; APUL, 2011; SHAH et al., 2013), dormitórios (DEVKOTA; SCHLACHTER; APUL, 2015), residenciais (NAZER et al., 2010; RACOVICEANU; KARNEY, 2010; MARINOSKI; GHISI, 2011; ANGRILL et al., 2012; MORALESPINZÓN et al., 2012; VARGAS-PARRA; VILLALBA; GABARRELL, 2013; ZHI-YUN; XIAO-YAN; YUJUN, 2013; GHIMIRE et al., 2014; MORALES-PINZÓN et al., 2014; RYGAARD et al., 2014; MORALES-PINZÓN et al., 2015; VIALLE et al., 2015; ANGRILL et al., 2017; GAO et al., 2016; JEONG et al., 2016; VALDEZ et al., 2016) e comerciais (CHANG; LEE; YOON, 2017; GHIMIRE et al., 2017). No entanto, a tipologia residencial unifamiliar foi a que teve o maior número de casos analisados na amostra estudada. No total, 17 artigos (68\%) se encaixaram nessa categoria. A Figura 9 apresenta os percentuais das tipologias das edificações utilizadas nos estudos realizados. Vale ressaltar que há trabalhos que estudaram mais de uma tipologia de edificação (MORALES-PINZÓN et al., 2012; MORALES-PINZÓN et al., 2014; MORALES-PINZÓN et al., 2015; JEONG et al., 2016; CHANG; LEE; YOON, 2017). 
Figura 9 - Tipologia das Edificações dos Estudos de Casos

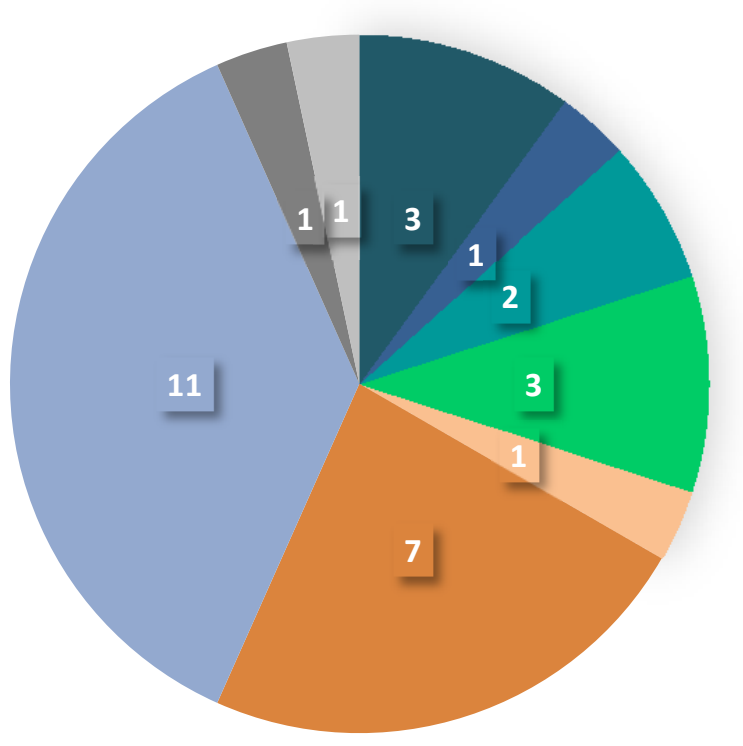

\author{
- Comercial \\ - Dormitório \\ - Esc olar Universida de \\ - Escritónio \\ - Ind ustrial \\ - Residenc ial Multifa milia r \\ — Residencial Unifa miliar \\ - Residencial Unifa miliar de \\ Interesse Social \\ - Residencial Unifa miliar Rural
}

Destes 20 artigos que abordaram a tipologia residência, 13 realizaram estudo em habitações unifamiliares, sendo que deste universo, apenas uma desenvolveu o trabalho em habitações de interesse social. Nesta publicação, Marinoski e Ghisi (2011), empregaram a metodologia baseada nos conceitos da ACV, conforme aplicada por Tavares (2006). Para as avaliações ambientais 4 cenários foram avaliados e abordou-se ainda os resultados comparativos entre três reservatórios constituídos de diferentes materiais: plástico reforçado com fibra de vidro, concreto e PEAD. Os autores propuseram ainda, uma variação no percentual da demanda de água pluvial entre 30,40 e $50 \%$, de acordo com o dimensionamento do reservatório, que poderia variar de 4 à $11 \mathrm{~m} 3$. Isto interferiu no percentual do potencial de aproveitamento de água pluvial. $\mathrm{O}$ estudo apresentou como resultados a unidade funcional e os indicadores de avaliação. Para este trabalho a unidade funcional era o volume de água potável consumido pela residência em um período de 20 anos, o que é equivalente à vida útil considerada para o sistema. Teve-se, portanto que, com o aumento do percentual de demanda de água pluvial, os indicadores ambientais utilizados apresentaram resultados cada vez melhores. Estes indicadores ambientais sugeridos associaram os dados de energia embutida (EE) por volume de água potável consumida $(\mathrm{MJ} / \mathrm{m} 3)$. Como resultados teve-se que os melhores valores ambientais foram obtidos com o cenário em que se adotou reservatório de plástico reforçado com fibra de vidro.

Outro aspecto analisado foram os usos finais previstos para a água proveniente do sistema de aproveitamento de água pluvial. Identificou-se que, na maioria dos casos, os usos previstos são destinados às bacias sanitárias. A Figura 10 apresenta também os demais usos para os quais a água de chuva foi destinada. 
Figura 10 - Usos finais da água proveniente do SPAAP

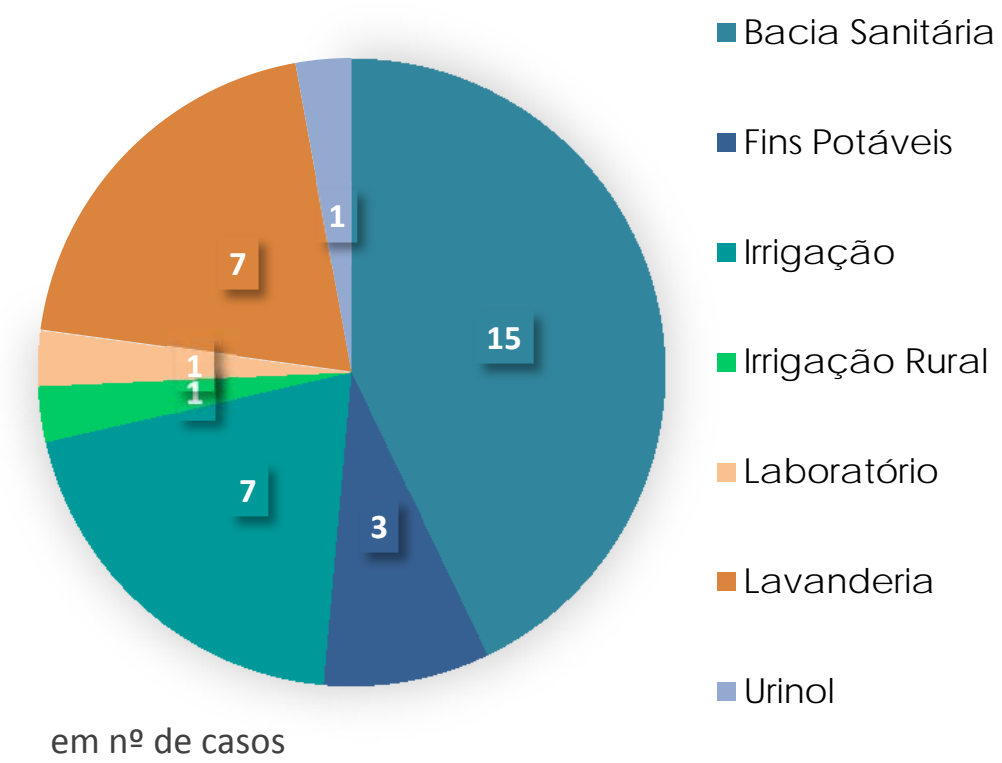

A bacia sanitária atinge $43 \%$ das ocorrências totais para os usos finais da água pluvial coletada. Vale ressaltar que dos 25 artigos, 15 realizaram uma abordagem com apenas um uso previsto para a água pluvial (NAZER et al., 2010; RACOVICEANU; KARNEY, 2010; ANAND; APUL, 2011; MARINOSKI; GHISI, 2011; WARD; BUTLER; MEMON, 2011; ANGRILL et al. 2012; MORALES-PINZÓN et al., 2012; SHAH et al., 2013; VARGAS-PARRA; VILLALBA; GABARRELL, 2013; ZHI-YUN; XIAO-YAN; YU-JUN, 2013; MORALES-PINZÓN et al., 2014; DEVKOTA et al., 2015; VIALLE et al., 2015; GAO et al., 2016; VALDEZ et al., 2016; ANGRILL et al., 2017;).

Verificou-se também as metodologias de ACV, bem como das bases de dados adotadas nas pesquisas investigadas. Em relação à $\mathrm{ACV}$, observou-se inicialmente se houve ou não a utilização de algum software para a realização das análises ambientais e quando utilizado, quais eram eles, conforme identifica-se na Figura 11. 
Figura 11- Softwares de ACV

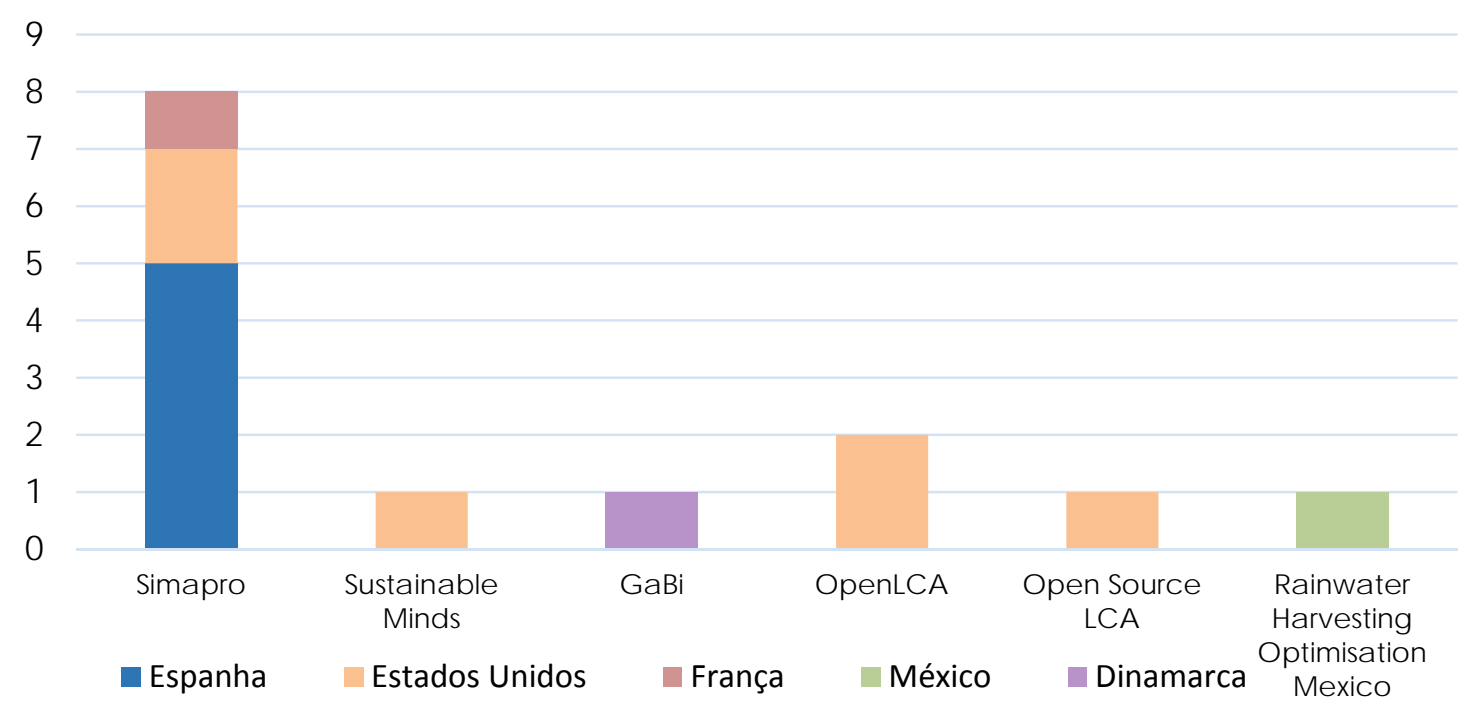

Percebe-se que das pesquisas que utilizaram software, o SimaPro® foi o mais utilizado pelos estudos encontrados no mapeamento (ANGRILL et al., 2012; MORALES-PINZÓN et al., 2012; GHIMIRE et al., 2014; MORALES-PINZÓN et al., 2014; MORALES-PINZÓN et al., 2015; VIALLE et al., 2015; JEONG et al., 2016; ANGRILL et al., 2017), apresentando um número de artigos 4 vezes maior que o segundo colocado, o OpenLCA (GHIMIRE et al., 2014; GHIMIRE et al., 2017). O SimaPro® foi desenvolvido na Holanda pela Pre-sustainability e possui vários métodos de AICV e bancos de dados (VINHAL, 2016), o que o torna tão interessante para ser aplicado para diferentes realidades. Além disso é uma ferramenta que apresenta uma certa flexibilidade, uma vez que possibilita que usuário realize uma modelagem do sistema do produto, transitando entre as diferentes metodologias e banco de dados oferecido (VINHAL, 2016). O SimaPro®, além de tudo é ainda uma ferramenta gratuita para a utilização com fins de pesquisa, o que justifica sua ampla recorrência nos estudos verificados.

Destaca-se ainda o Rainwater Harvesting Optimization, um simulador projetado no Excel囚. Este programa simula a demanda de água, otimiza o dimensionamento dos reservatórios e compara os 3 indicadores ambientais sugeridos no estudo: Global Warming Potential - GWP, Cumulative Energy Demand - CED e o Net Present Value - NVP. O indicador GWP indica o potencial de aquecimento global (KgCO2eq./m3), o CED indica a EE pelo volume de água utilizada durante a vida útil do sistema (KWh/m3) e o NVP como o valor presente líquido de cada cenário. Este trabalho teve como objetivo calcular e comparar as emissões de gases estufa, energia e custos do ciclo de vida de 5 diferentes configurações de SPAAP em edificações supridas também pela concessionária. O simulador é utilizado tanto para edificações comerciais, quanto em edificações residenciais uni e multifamiliares. No entanto, ele realiza essas simulações apenas para a Cidade do México.

Mais uma análise que o MSL pôde oferecer embasamento, foi quanto às metodologias de $A C V$ e também com relação às bases de dados adotadas. Em relação à metodologia utilizada para a ACV de cada estudo, verificou-se que a mais empregada é a apresentação dos dados quanto à EE e ao dióxido de carbono equivalente embutido (EC) (NAZER et al., 2010; RACOVICEANU; KARNEY, 2010; MARINOSKI; GHISI, 2011; WARD; BUTLER; MEMON, 2011; ZHI-YUN; XIAO-YAN; YU-JUN, 2013; DEVKOTA; SCHLACHTER; APUL, 2015; VALDEZ et al., 2016; CHANG; LEE; YOON, 2017), o que se deve provavelmente por se ter uma maior facilidade de acesso aos procedimentos metodológicos. Outra base de dados bastante utilizada é Economic Input-Output Life Cycle Assessment - EIO-LCA Model (RACOVICEANU; KARNEY, 2010; ANAND; APUL, 2011; DEVKOTA; SCHLACHTER; APUL, 2015; GAO et al., 2016), presente em 20\% dos artigos avaliados. A Figura 12 apresenta os demais 
métodos abordados.

Figura 12 - Métodos de ACV

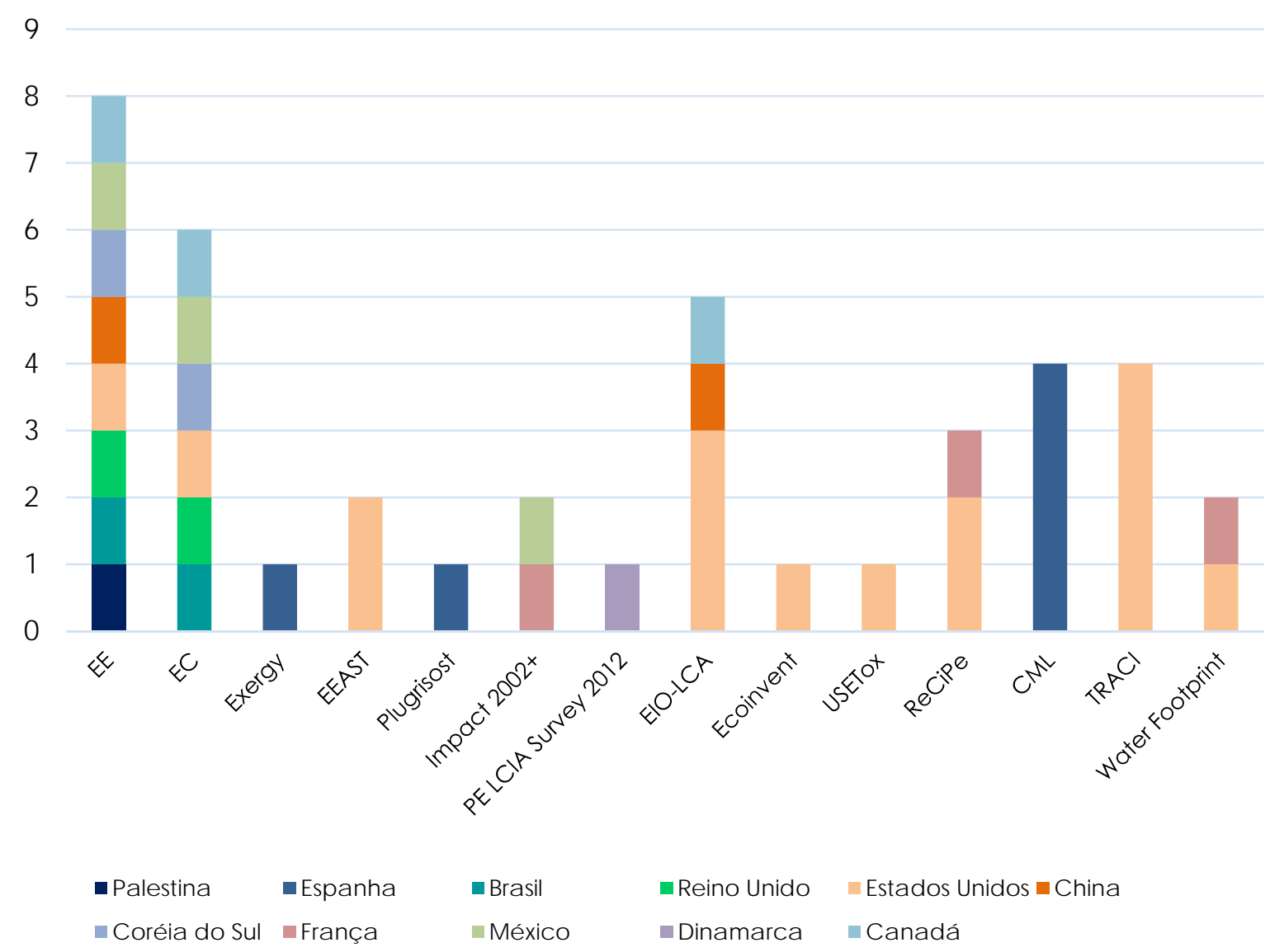

Verificou-se ainda que as ACVs que apresentaram seus resultados por meio de EE e EC, utilizaram em sua maioria dados provenientes de bibliografias (RACOVICEANU; KARNEY, 2010; MARINOSKI; GHISI, 2011; WARD; BUTLER; MEMON, 2011; ZHI-YUN; XIAO-YAN; YU-JUN, 2013; DEVKOTA; SCHLACHTER; APUL, 2015) e os demais artigos utilizaram suas bases de dados de outras fontes. Além disso, percebeu-se que as primeiras publicações apresentavam os dados de impacto ambiental sob o formato de EE e EC.

Além disso, verificou-se dentre os artigos aderentes, dois trabalhos que tinham como objetivo do desenvolvimento de novos programas para avaliação ambiental. O primeiro deles é desenvolvido por Devkota et al. (2015) sob o nome de EEAST Model. O programa é baseado na metodologia apresentada pelo Software TRACl e utiliza as bases de dados $\mathrm{GaBi} \circledast$ e Ecoinvent $\circledast$. Busca apresentar dados que mostrem as diferenças de resultados entre as configurações de sistemas através de um indicador, que é dado pela razão entre demanda e o suprimento de água pluvial. Os resultados da pesquisa apresentaram ainda, análises de indicadores por usuário e por área de captação $(800 \mathrm{~kg}$ de CO2/pessoa e 12KgCO2/pé2).

O Segundo trabalho é desenvolvido por Morales-Pinzón et al. (2015) e sugere o Plugrisost como uma ferramenta para facilitar a gestão e o planejamento de SPAAP e do uso de águas cinzas, especialmente na escala de planejamento urbano. O programa integra duas diferentes ferramentas metodológicas, a análise de ciclo de vida com a simulação dinâmica, para avaliar custos econômicos e os impactos ambientais potenciais de sistemas alternativos de suprimento de água. Auxilia ainda no 
dimensionamento dos reservatórios e estima os custos e os quantitativos das análises ambientais, apresentando-se como um programa em fase de criação, porém com o objetivo de tornar-se bastante completo.

É interessante ressaltar ainda, que apesar de mais de 36\% dos artigos terem apresentado avaliações não somente ambientais, como também econômicas (NAZER et al., 2010; RACOVICEANU; KARNEY, 2010; ANAND; APUL, 2011; MARINOSKI; GHISI, 2011; DEVKOTA et al., 2013; DEVKOTA; SCHLACHTER; APUL, 2015; MORALES-PINZÓN et al., 2015; GAO et al., 2016; VALDEZ et al., 2016), porém identificou-se apenas um artigo que propôs uma avaliação também social (NAZER et al., 2010). Para essa avaliação social, utilizou-se especialmente de técnicas de entrevistas e questionários com os usuários do estudo de caso.

Além da ACV, também verificou-se a origem das bases de dados adotadas. Foi possível identificar uma gama bastante ampla de bases de dados para acesso às informações necessárias para os cálculos ambientais. Nota-se que a maioria dos dados são obtidos de fontes bibliográficas ou de conselhos registrados. Mas em relação à uma base de dados específica, tem-se que a Ecoinvent é a mais utilizada (ANGRILL et al.; 2012; MORALES-PINZÓN et al., 2012; GHIMIRE et al., 2014; MORALES-PINZÓN et al., 2014; DEVKOTA et al., 2015; MORALES-PINZÓN et al., 2015; VIALLE et al., 2015; JEONG et al., 2016; VALDEZ et al., 2016; ANGRILL et al., 2017; CHANG; LEE; YOON, 2017; GHIMIRE et al., 2017). A Figura 13 apresenta os dados obtidos neste tópico.

Figura 13 - Bases de dados

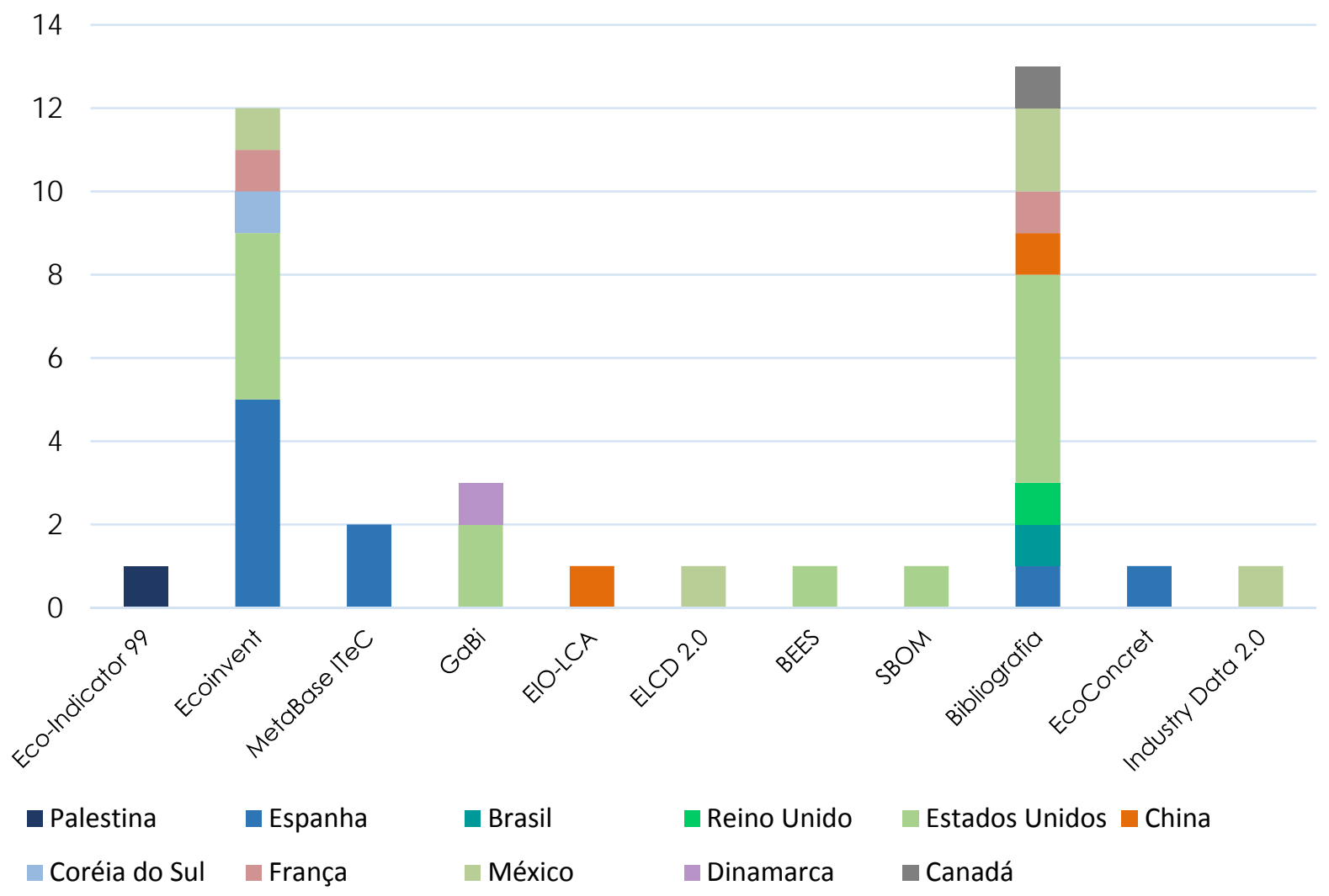

O Ecoinvent ${ }^{\circledR}$ é uma ferramenta que pode ser utilizada tanto como metodologia, quanto como base de dados. Ela foi desenvolvida pelo Instituto Federal Suíço para Pesquisa e Testes de Materiais (EMPA) em parceria com diversos institutos governamentais suíços. Sua ampla utilização é justificada por 
apresentar uma quantidade de quase 10 mil inventários, (VINHAL, 2016) sendo considerada uma base de dados internacional.

Em relação à escolha das bases de dados, três artigos em específico (RACOVICEANU; KARNEY, 2010; JEONG et al., 2016; CHANG; LEE; YOON, 2017) deixaram explícita a preocupação com o uso de dados locais e caso estes não estivessem disponíveis, seriam realizadas adaptações para se adequarem, o quanto possível, à realidade local. Dos trabalhos aderentes, 9 utilizaram mais de uma base de dados para a obtenção dos dados ambientais (RACOVICEANU; KARNEY, 2010; ANAND; APUL, 2011; MARINOSKI; GHISI, 2011; WARD; BUTLER; MEMON, 2011; ANGRILL et al.; 2012; DEVKOTA et al., 2013; VARGAS-PARRA; VILLALBA; GABARRELL, 2013; ZHI-YUN; XIAO-YAN; YUJUN, 2013; DEVKOTA et al., 2015; DEVKOTA; SCHLACHTER; APUL, 2015; VIALLE et al., 2015; GARCÍA-MONTOYA et al.; 2016; VALDEZ et al., 2016; JEONG et al., 2016; ANGRILL et al., 2017; GHIMIRE et al., 2017). No entanto, nenhum dos artigos realizou análises comparativas e qualitativas quanto à origem das bases de dados.

Por fim, a vida útil dos SPAAPs foi verificada e a maioria dos artigos adotou o tempo para 50 anos (NAZER et al., 2010; ANAND; APUL, 2011; MORALES-PINZÓN et al., 2012; SHAH et al., 2013; VARGAS-PARRA; VILLALBA; GABARRELL, 2013; GHIMIRE et al., 2014; MORALES-PINZÓN et al., 2014; RYGAARD et al., 2014; MORALES-PINZÓN et al., 2015; VIALLE et al., 2015; JEONG et al., 2016; ANGRILL et al., 2017; GHIMIRE et al., 2017). A Figura 14 apresenta esses dados divididos por países.

Figura 14 - Vida útil dos SPAAPs

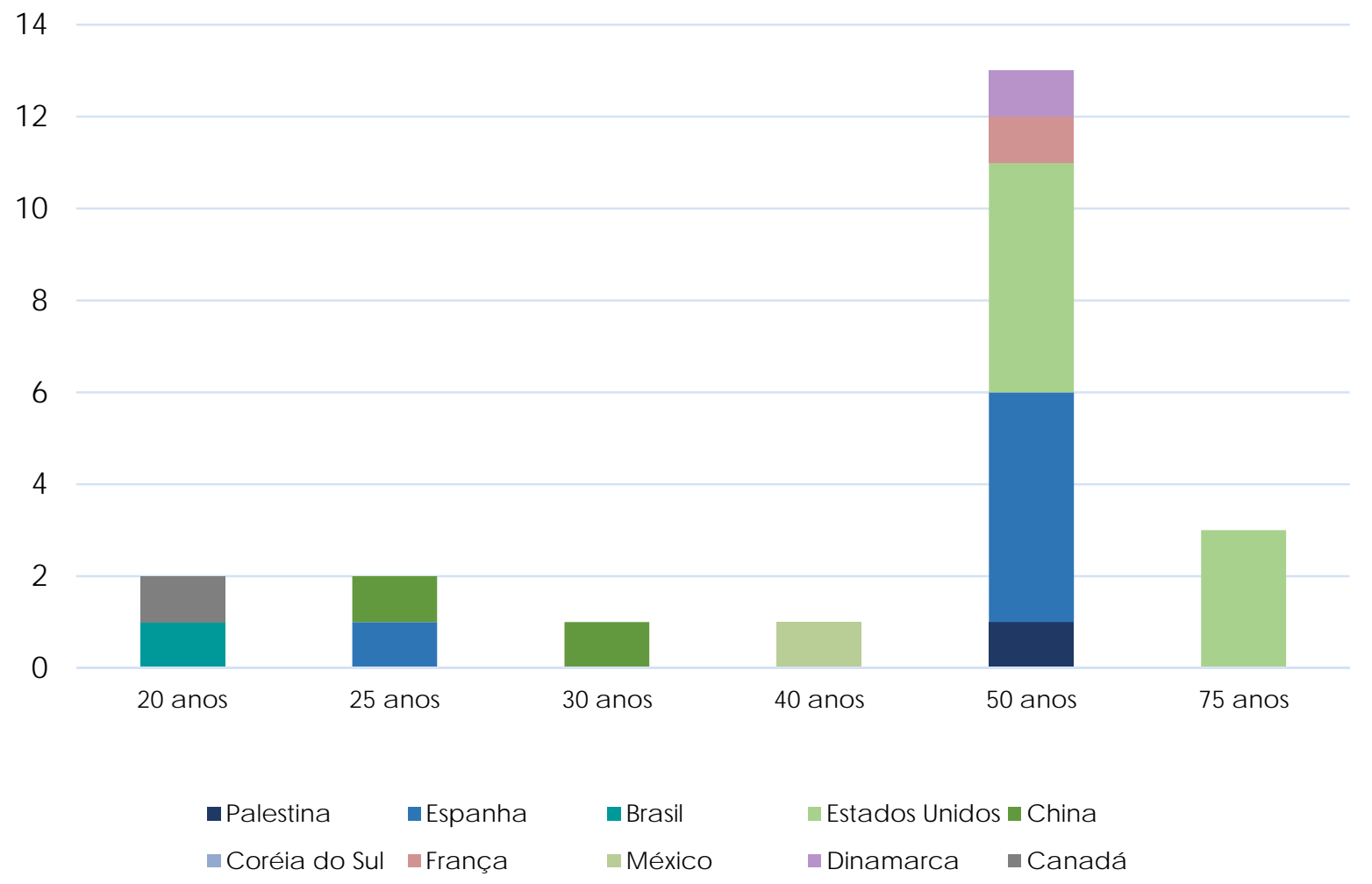




\section{Conclusões}

Partindo das análises realizadas por meio do MSL, foi possível verificar as lacunas do conhecimento que existem na área abordada, assim como os aspectos que podem ser aderidos à pesquisa em questão. Inicialmente, observa-se que o tema é ainda relativamente recente, uma vez que os artigos encontrados datam dos últimos 7 anos. Além disso, verificou-se que os Estados Unidos é o país que mais tem abordado o tema, apontando ainda que no Brasil, há apenas uma pesquisa sobre o assunto (MARINOSKI; GHISI, 2011).

Outro ponto é, o fato de que as pesquisas apresentadas embasaram seus métodos com abordagens de ACV diferentes, algumas apresentando apenas e energia embutida e emissões (NAZER et al.., 2010; RACOVICEANU; KARNEY, 2010; ANAND; APUL, 2011; MARINOSKI; GHISI, 2011; WARD; BUTLER; MEMON, 2011; DEVKOTA et al., 2013; SHAH et al., 2013; DEVKOTA; ZHI-YUN; XIAO-YAN; YU-JUN, 2013; SCHLACHTER; APUL, 2015; VALDEZ et al., 2016; CHANG; LEE; YOON, 2017). Porém as demais destrinchando ainda para outros tipos de impactos de midpoint ou endpoint (ANGRILL et al., 2012; MORALES-PINZÓN et al., 2012; GHIMIRE et al., 2014; MORALES-PINZÓN et al., 2014; RYGAARD et al., 2014; DEVKOTA et al., 2015; MORALES-PINZÓN et al., 2015; VIALLE et al., 2015; GAO et al., 2016; GARCÍA-MONTOYA et al.; 2016; JEONG et al., 2016; ANGRILL et al., 2017; GHIMIRE et al., 2017).

Percebe-se que para a ICV, foram utilizadas várias bases de dados, concluindo que isso irá se referir frente ao objetivo e escopo adotados para o trabalho, bem como com a região em que ele é realizado, para que os dados sejam mais verossímeis. É possível identificar também que o estudo de caso é uma alternativa viável de modelo de pesquisa, uma vez que todos os artigos aderentes ao MSL adotaram este modelo de pesquisa.

Em relação ao trabalho realizado no Brasil, as técnicas metodológicas apresentaram-se satisfatórias, podendo serem empregadas neste estudo. No entanto, ambas pesquisas irão se diferir nos aspectos dos resultados buscados. Na pesquisa realizada por Marinoski e Ghisi (2011), quanto aos aspectos ambientais, foram comparados os sistemas com e sem aproveitamento de água pluvial com a simulação de diferentes volumes e materiais de reservatórios. O que se propõe para este estudo são as comparações de viabilidade ambiental para diferentes configurações de SPAAP constituídas dos mesmos materiais componentes, bem como realizar análises comparativas entre bases de dados provenientes de diferentes realidades, uma buscando dados de países em desenvolvimento e a outra de países desenvolvidos.

\section{Agradecimentos}

Agradecemos a CAPES pela concessão de bolsa de mestrado durante a execução desta pesquisa.

\section{Referências}

ANAND, C.; APUL, D.S. Economic and environmental analysis of standard, high efficiency, rainwater flushed, and composting toilets. 2011.Disponível em: doi:10.1016/j.jenvman.2010.08.005.

ANGRILL, S.; FARRENY, R.; GASOL, C. M.; GABARRELL, X.; VIÑOLAS, B.; JOSA, A.; RIERADEVALL, J.; Environmental analysis of rainwater harvesting infrastructures in diffuse and compact urban models of Mediterranean climate. The International Journal of Life Cycle Assessment, v. 17, f. 1, p. $25-42,2012$.

ANGRILL, S.; SEGURA-CASTILLO, L.; PETIT-BOIX, A.; RIERADEVALL, J.; GABARRELL, X.; JOSA, A. Environmental performance of rainwater harvesting strategies in Mediterranean buildings. International Journal of Life Cycle Management, vol. 22, p. 398-409, 2017. 
BAILEY, J.; BUDGEN, D.; TURNER, M.; KITCHENHAM, B.; BRERETON, P.; LINKMAN, S. Evidence relating to Object-Oriented software design: A survey. In: FIRST INTERNATIONAL SYMPOSIUM ON EMPIRICAL SOFTWARE ENGINEERING AND MEASUREMENT, Anais eletrônicos... Computer Society, 2007. 3p. DOI: 10.1109/ESEM.2007.58

CAIXA ECONÔMICA FEDERAL. Minha Casa Minha Vida. Disponível em: http://mcmv.caixa.gov.br/minha-casa-minha-vidal, acesso em: 18/10/2015.

CHANG, J.; LEE, W.; YOON, S. Energy consumptions and associated greenhouse gas emissions in operation phases of urban water reuse systems in Korea. 2017. Disponível em: http://dx.doi.org/10.1016/j.jclepro.2016.09.131.

COSTA, C. H. A.; STAUT, S. L. S.; ILHA, M. S. O. Projeto de Sistemas Prediais Hidráulicos Sanitários com Bim: Mapeamento da Literatura, In: XV ENCONTRO NACIONAL DE TECNOLOGIA NO AMBIENTE CONSTRUÍDO, Anais eletrônicos... 2014, Maceió - AL 10p.

DEVKOTA, J.; BURIAN, S. J.; TAVAKOL-DAVANI, H.; APUL, D. Introducing demand to supply ratio as a new metric for understanding life cycle greenhouse gas (GHG) emissions from rainwater harvesting systems Journal of Cleaner Production, Elsevier Ltd., vol. [s.n.], p. 1-11, 2015.

DEVKOTA, J.; SCHLACHTER, H.; ANAND. C.; PHILLIPS, R.; APUL, D. Development and application of EEAST: A life cycle based model for use of harvested rainwater and composting toilets in buildings. Disponível em: http://dx.doi.org/10.1016/j.jenvman.2013.09.015.

DEVKOTA, J.; SCHLACHTER, H.; APUL, D. Life cycle based evaluation of harvested rainwater use in toilets and for irrigation, Journal of Cleaner Production, Elsevier Ltd., vol. 95, p. 311-321, fev. 2015.

ENGSTRÖM, E.; RUNESON, P. Software product line testing: A systematic mapping study. Information and Software Technology, Journal Homepage: www.elsevier.com/locate/infsof, v. 53, p. 2-13, 2011.

FUNDAÇÃO JOÃO PINHEIRO. Déficit Habitacional no Brasil - Referência 2007. Ministério das Cidades, Secretaria Nacional de Habitação, Brasília, jun. 2009, 129p. Disponível em: http://www.fjp.mg.gov.br/index.php/produtos-e-servicos1/2742-deficit-habitacional-no-brasil-3, acesso em 17/10/2015.

FUNDAÇÃO JOÃO PINHEIRO. Déficit Habitacional no Brasil - Referência 2008. Ministério das Cidades, Secretaria Nacional de Habitação, Brasília, abr. 2011, 140p. Disponível em: http://www.fjp.mg.gov.br/index.php/produtos-e-servicos1/2742-deficit-habitacional-no-brasil-3, acesso em 17/10/2015.

FUNDAÇÃO JOÃO PINHEIRO. Déficit Habitacional no Brasil - Referência 2009. Fundação João Pinheiro, Centro de Estatísticas e Informações, Belo Horizonte, set. 2012, 200p. Disponível em: http://www.fjp.mg.gov.br/index.php/produtos-e-servicos1/2742-deficit-habitacional-no-brasil-3, acesso em 17/10/2015.

FUNDAÇÃO JOÃO PINHEIRO. Déficit Habitacional no Brasil - Referência 2010. Fundação João Pinheiro, Centro de Estatísticas e Informações, Belo Horizonte, nov. 2013, 78p. Disponível em: http://www.fjp.mg.gov.br/index.php/produtos-e-servicos1/2742-deficit-habitacional-no-brasil-3, acesso em 17/10/2015.

FUNDAÇÃO JOÃO PINHEIRO. Déficit Habitacional no Brasil - Relatório 2011 - 2012. Fundação João Pinheiro, Centro de Estatísticas e Informações, Belo Horizonte, 2015, 126p. Disponível em: http://www.fjp.mg.gov.br/index.php/produtos-e-servicos1/2742-deficit-habitacional-no-brasil-3, acesso em 17/10/2015.

GAO, H.; ZHOU, C.; LI, F.; HAN, B.; LI, X. Economic and environmental analysis of five Chinese rural toilet technologies based on the economic inputeoutput life cycle assessment. Disponível em: http://dx.doi.org/10.1016/j.jclepro.2015.12.089.

GARCÍA-MONTOYA, M.; SENGUPTA, D.; NAPOLES-RIVERA, F.; PONCE-ORTEGA, J. M.; ELHALW, M. M. Environmental and economic analysis for the optimal reuse of water in a residential complex. Disponível em: http://dx.doi.org/10.1016/j.jclepro.2015.06.109. 
GEHARDT, T. E.; SILVEIRA D. T. Métodos de Pesquisa. $1^{\text {a }}$ Ed. Porto Alegre: Editora da UFRGS, 2009. $120 \mathrm{p}$.

GHIMIRE, R. S.; JOHNSTON, J. M.; INGWERSEN, W. W.; HAWKINS, T. R. Life Cycle Assessment of Domestic and Agricultural Rainwater. Environmental Science and Technology, Ohio, United States, v. $48, \quad$ n. 7 , p. 4069-4077, 2014. DOI: 10.1021/es500189f. Disponível em: dx.doi.org/10.1021/es500189f, 2014.

GHIMIRE, R. S.; JOHNSTON, J. M.; INGWERSEN, W. W.; SOJKA, S. Life cycle assessment of a commercial rainwater harvesting system compared with a municipal water supply system. 2017. Disponível em: DOI: 10.1016/j.jclepro.2017.02.025.

JEONG, H.; BROESICKE, O. A.; DREW, B.; LI, D.; CRITTENDEN, J. C. Life cycle assessment of low impact development technologies combined with conventional centralized water systems for the City of Atlanta, Georgia, 2016. DOI: 10.1007/s11783-016-0851-0.

KITCHENHAM, B.; PRETORIUS, R.; BUDGEN, D.; BRERETON, O. P.; TURNER, M.; NIAZI, M.; LINKMAN, S. Systematic literature reviews in software engineering: A tertiary study. Information and Software Technology, Journal Homepage: www.elsevier.com/locate/infsof, v. 52, p. 792-805, 2010.

MANO, R. S. Captação Residencial de Água de Chuva para Fins não potáveis em Porto Alegre: Aspectos Básicos da Viabilidade e Benefícios do Sistema. 2004. 177p. Dissertação (Mestrado em Engenharia) - Programa de Pós-Graduação em Engenharia Civil, Escola de Engenharia, Universidade Federal do Rio Grande do Sul, Porto Alegre, RS, jan. 2004.

MARINOSKI, A. K. Método para avaliação de viabilidade ambiental e econômica de sistemas de aproveitamento de água pluvial. 2010. 159 p. Dissertação (Mestrado em Engenharia Civil) - Centro Tecnológico, Departamento de Engenharia Civil, Universidade Federal de Santa Catarina, Florianópolis, SC, nov. 2010.

MARINOSKI, A. K.; GHISI, E. Assessment of the environmental impact and investment feasibility analysis of rainwater use in houses. Ravage of the Planet III, [United States], v. 148, ISSN 1743-3541, 2011. DOI:10.2495/RAV110361, 2011.

MORALES-PINZÓN, T.; LURUEÑA, R.; GABARRELL, X.; GASOL, C. M.; RIERADEVALL, J. Financial feasibility and environmental analysis of potential rainwater harvesting systems: A case study in Spain. Resources, Conservation and Recycling, vol. 69, p. 130-140, 2012.

MORALES-PINZÓN, T.; LURUEÑA, R.; GABARRELL, X.; GASOL, C. M.; RIERADEVALL, J. Financial and environmental modelling of water hardness - Implications for utilising harvested rainwater in washing machines. Science of the Total Environment, vol. 470-471, p. 1257-1271, 2014.

MORALES-PINZÓN, T.; LURUEÑA, R.; GABARRELL, X.; GASOL, C. M.; RIERADEVALL, J. Modelling for economic cost and environmental analysis of rainwater harvesting systems. Journal of Cleaner Production, vol. 87, p. 613-623, 2015.

NAZER, D. W.; SIEBEL, M. A.;VAN DER ZAAG, P.; MIMI, Z.; GIJZEN, H. J. A Financial, Environmental and Social Evaluation of Domestic Water Management Options in the West Bank, Palestine DOI 10.1007/s11269-010-9667-z

ONU: ORGANIZAÇÃO DAS NAÇÕES UNIDAS. Declaração Universal dos Direitos Humanos. Paris, 1948, 17 p. Disponível em: http://www.dudh.org.br/wp-content/uploads/2014/12/dudh.pdf, acesso em: $16 / 12 / 2015$.

RACOVICEANU, A. I.; KARNEY, B. W.; Life-Cycle Perspective on Residential Water Conservation Strategies. 2010. DOI: 10.1061/ ASCE 1076-0342 2010 16:1 40

RUIZ, J. A.; GRANJA, A. D. Um Mapeamento Sistemático da Literatura Sobre a Relação entre Valor e Colaboração na Construção, In: $8^{\circ}$ SIMPÓSIO BRASILEIRO DE GESTÃO E ECONOMIA DA CONSTRUÇÃO, INOVAÇẪO E SUSTENTABILIDADE, Anais eletrônicos... 2013, Salvador - BA, 14p.

RYGAARD, M.; GODSKESEN, B.; JØRGENSEN, C.; HOFFMANN, B. Holistic assessment of a secondary water supply for a new development in Copenhagen, Denmark. 2014. Disponível em: http://dx.doi.org/10.1016/j.scitotenv.2014.07.078. 
SHAH, D.; PATEL, P.; KUDO, P.; STEINBERG, A.; HEROLD, W. Feasibility of Rainwater Harvesting on Scott Laboratory: Rainwater Harvesting at OSU. IEEE 2013 Global Humanitarian Technology Conference. DOI: 978-1-4799-2402-8/13/\$31.00

TAVARES, S. F. Metodologia De Análise do Ciclo de Vida Energético de Edificações Residenciais Brasileiras. 2006. 225p. Tese (Doutorado em Engenharia Civil) - Programa de PósGraduação em Engenharia Civil, Universidade Federal de Santa Catarina, Florianópolis, SC, abr. 2006.

VALDEZ, M. C.; ADLER, I.; BARRETT, M.; OCHOA, R.; PÉREZ, A. The Water-Energy-Carbon Nexus: Optimising Rainwater Harvesting in Mexico City. 2016. DOI: DOI 10.1007/s40710-016-0138-2.

VARGAS-PARRAA, M. V.; VILLALBAA, G.; GABARRELL, X. Applying exergy analysis to rainwater harvesting systems to assess resource efficiency. Resources, Conservation and Recycling, vol. 72 , p. 50-59, 2013.

VIALLE, C.; BUSSET, G.; TANFIN, L.; MONTREJAUD-VIGNOLES, M.; HUAU, M.-C.; SABLAYROLLES, C. Environmental analysis of a domestic rainwater harvesting system: A case study in France. 2015. Disponível em: http://dx.doi.org/10.1016/j.resconrec.2015.07.024.

VINHAL, L. D. Estudo De Indicadores Ambientais De Blocos Cerâmicos Com Base Em Avaliação Do Ciclo De Vida, Considerando O Contexto Brasileiro. Dissertação (Mestrado - Área de concentração de sistemas construtivos), São Carlos, Programa de Pós-Graduação em Construção Civil, Universidade Federal de São Carlos, São Carlos, 2016.

WARD, S.; BUTLER, D.; MEMOM, F. A. Benchmarking energy consumption and CO2 emissions from Rainwater-harvesting systems: na improved method by proxy. Water and Environment Journal, vol. 26, p. $184-190$.

YRUSKA, I. Aproveitamento da Água de Chuva para Consumo não Potável em Condomínios Horizontais da Cidade De João Pessoa - PB. 2008. 107p. Dissertação (Mestrado em Engenharia Urbana) - Centro de Tecnologia, Universidade Federal da Paraíba, João Pessoa, jul. 2008.

ZHI-YUN, J.; XIAO-YAN, L.; YU-JUN, M. Water and Energy Conservation of Rainwater Harvesting System in the Loess Plateau of China. Journal of Integrative Agriculture, vol. 12, p. 1389-1395, 2013. 